\title{
Freirean Participatory Approach: Developing Interactive Listening Skills in the English as a Second Language (ESL) Classroom
}

\author{
Hlaviso A. Motlhaka \\ Free State University, School of Social Science and Language Education, RSA \\ Newman Wadesango \\ University of Fort Hare, Teaching and Learning Centre, RSA, mothakaha@ufs.ac.za
}

\section{Doi:10.5901/mjss.2014.v5n11p101}

\begin{abstract}
Drawing on Paulo Freire's participatory approach, this paper aims to analyze learning and teaching strategies that foster student motivation and English as a Second Language (ESL) listening to enhance ESL learning. This approach allows students to critically think about their educational goals and identify their strengths and weaknesses in the production of knowledge. Empirical studies from 1992 to 2013 were collected and analyzed guided by content analysis approach. This paper demonstrates that cooperative learning promotes a non-threatening environment conducive for learning. Findings confirm that lecturer talk and lecturers' questions elicit students' use of ESL through speech production. The findings suggest that the use of student questions to promote communication from diverse perspectives is a significant motivational tool. Finally, after demonstrating the implications of learning and teaching strategies, this paper offers a set of recommendations to help lecturers and researchers in promoting student motivation and developing ESL listening.
\end{abstract}

Keywords: Interactive listening, cooperative learning, teachers' questions, students' questions, participatory approach

\section{Introduction}

Listening skills are an essential aspect of the development of motivation which empowers students to develop their communication and critical thinking skills necessary for functioning competently in the ESL classroom, the workplace, the home and other places where language learners engage with the public. The development of active listening is essential to students' ability to negotiate language outside of the classroom. As a result, Hunsaker (as cited in Swain, Friehe, \& Harrington, 2004:48) and Feyten (as cited in Vasiljevic, 2010:41) affirmed that "an estimated 80 percent of what we know is acquired through listening and 45 percent of communication" to demonstrate the significance of interactive listening skills for successful ESL learning and acquisition either at home, at school or in the workplace. Given the relevance of this statement, it is clear that successful ESL interaction either between school teachers and learners, parents and children, medical personnel and patients or law enforcement officials and suspects, is primarily dependent on effective interactive listening skills (Thompson, Leintz, Nevers, \& Witkowski,2004).

Interactive listening skills also improve learners' interpersonal skills, which enable them to establish a healthy relationship with their conversation partners. In consideration of the above-mentioned information about interactive listening in language learning, it is quite clear that interactive listening is imperative in our daily life as we share ideas because we spend more time listening to one another in order to respond appropriately in overall language learning as compared to other learning skills. In the ESL classroom, it is easy to see that interactive listening plays a significant role in enhancing ESL students' comprehensible input and advancement of ESL learning when lecturers create lesson plans that encourage students to connect the content to their own lives through listening because they are then able to learn on their own. For these reasons, this research contributes to a better understanding of the perceived ESL students' motivation and the strategies used by ESL lecturers.

In this instance, it is apparent that a comprehensive and effective listening curriculum should be introduced across educational disciplines beyond the ESL classroom to optimize students' listening skills. Learning to listen effectively is a continuously changing process in which lecturers need to be mindful of individual leaner background knowledge and preferences (Thompson, Leintz, Nevers, \& Witkowski:2004) in order to model listening strategies and provide listening practice in authentic situations: those listening situations that learners are most likely to encounter in using ESL outside of the classroom. This may include giving students listening activities that require them to relate what has been said during 
whole class discussion or after watching a movie in which students will be able to assess their listening skills based on their recall of what has been said as well as evaluate their learning goals in relation to their listening ability.

This paper might help ESL lecturers, policy makers and curriculum designers to make informed decisions, through greater understanding of the attitudes and behaviors in active listening of ESL students and lecturers towards what constitutes successful ESL learning. The paper intends to provide lecturers and students with effective ESL interactive listening techniques and activities, which tend to promote students' confidence to use language spontaneously and appropriately. Hopefully, this paper will provide alternative solutions to inadequate levels of ESL proficiency among most learners in South African universities who pass through the school system despite using ESL across the school curriculum and elsewhere in the world (Schlebusch \& Thobedi, 2004).

More than that, this paper seeks to raise lecturers' critical pedagogical awareness of post-methods and reflective approaches in classroom settings to optimize students' ESL proficiency. In this context, critical pedagogical awareness and reflective approaches refer to teachers' ability to appropriately understand and deal with day-to-day educational students' limitations in developing pedagogical structures that engage them in a successful educational process.

\section{Study Objectives}

The main aim of this paper is to review and critique ESL strategies and activities in teaching ESL through interactive listening methodology in an effort to enhance students' listening competence. This study focuses on the following specific objective:

- Introduce and recommend interactive listening methodology as a key component in the professional development of lecturers, offering key strategies and pedagogical tools.

\section{Research Questions}

This study attempts to answer the following questions:

1. How does interactive listening optimize learning in the ESL classroom?

2. What kinds of learning strategies and activities are suitable for interactive listening?

\section{Theoretical Framework}

This paper adopts Paul Freire's Participatory Approach as a theoretical framework because it advocates a meaningful interaction wherein students are able to reflect on their relationship to the world they live in and provides themselves with a means to shape their world (Blackburn, 2000). In this case, discussion among students and teachers becomes the basis for literacy development, reflection and action for improvement of their English proficiency. Hence, this paper focuses holistically on students in the context of real-world learning situations in promoting cognitive, motivational, and social, and individual difference factors influencing their learning. McCombs and Miller (2007) build upon this reasoning by concluding that students become fully engaged when lecturers find ways to empower them. As a result, students reflect on their own learning, share their insights with their peers, apply new learning to real-life, authentic experiences, and contribute to existing curricula. This view promotes learner-autonomy and motivates students to further learn ESL outside the classroom using any learning material at their disposal.

\section{Research Methodology}

This paper utilizes qualitative techniques for qualitative meta-analysis to establish concise and comprehensive knowledge in the field of this paper as defined by Timulak (2009). From this lens, we used content analysis approach to achieve the objective of this paper. Based on the findings and discussion, we formulated suggestions and recommendations in an effort to develop interactive listening skills as a way of enhancing students' ESL proficiency.

\section{Data Collection}

We used content analysis method as a research framework for this paper to locate and select texts that are relevant to our research questions instead of research techniques such as interview and questionnaire to collect data, as Franzosi (2003) asserted that content analysis is a good tool for teasing out the main themes expressed in a text. It was used to determine the presence of certain concepts and themes within texts to quantify this study in an objective manner and 
texts were selected in accordance to the information they could bring to the study.

We reviewed and critiqued empirical scholarly articles which gave detailed information and future inquiry into the phenomena under study. We found few studies about the Asian and the African perspectives and more studies of the North American perspective. This points to the need for studies outside the American context in this field. Scholarly works we chose presented more in-depth analyses and insightful critiques. Clearly then, we are confident that the scholarly works we analyzed gave a holistic picture of the situation under study.

\section{Data Analysis}

We extracted and coded the target information which was defined in the research questions and included in the main themes that constitute analysis units. We then analyzed the data by describing the findings according to target themes, interpreting and making inferences on the research results. As Kaplan pointed out that "content analysis is the technique that attempts to characterize the meanings in a given body of discourse in a systematic and qualitative fashion" (as cited in Lewis-Beck, Bryman, \& Liao, 2004:186). Accordingly, we used qualitative content analysis to generate themes related to our research questions as explained by Patton (2002), when he claimed that qualitative content analysis looks for insights in which situations, settings, styles, meanings and nuances are key topics to have a better understanding of the phenomenon under study. Continuous comparison of articles was fundamental to the analysis of our data throughout this study.

The following research questions guided the analysis of every article in this study:

1. How does interactive listening optimize learning in the ESL classroom?

2. What kinds of learning strategies and activities are suitable for interactive listening?

Then, after discussing themes as they connect to the research questions, we provided pedagogical recommendations and suggestions that emerge from the results of this study.

\section{Results and Discussion}

After outlining the methodological grounds to be employed in this study, this section provides detailed results from analyzing empirical scholarly articles related to interactive listening and learning. This section merges through the analysis of data into interactive listening which connects to our thesis statement about the development of ESL listening, which in turn improves students' ability to learn ESL. These findings are a vehicle to reconstitute the classroom as a zone of mutual respect. Comporting with the above-discussed theme, we have organized our findings on interactive ESL listening into subcategories consisting of literature from 1992 to 2013.

Teacher talk. Teacher talk develops interactive ESL listening because it is not limited to any specific verbal communication by lecturers. It involves the broadest range of a lecturer's utterances in the classroom, from an instructional explanation to a classroom management directive and use of facial expression (Sharpe, 2008). In other words, teacher talk can serve as a linguistic device, medium, and resource to assist student learning. This particular way of talking enables lecturers to facilitate students' comprehension of English by simplifying language structures, such as vocabulary and pronunciation in consideration of the regional dialect and then gradually moving to a standard dialect. Much teacher talk relates to questions asked to assist learners in improving learning, practicing skills, or using the target language (Cullen, 2002; Lee, 2006). This type of communication fosters mutual understanding and collaborative development of new knowledge between lectueres and students.

It also serves as an advantageous and motivating tool for students whose ESL is at an intermediate level to boost their confidence and self-esteem to use ESL spontaneously beyond the classroom given minimum exposure of ESL outside the classroom (Incecay, 2010; Rezaee \& Farahian, 2012). Therefore, the type of ESL usage between lecturers and students develop ESL listening and students' comprehension which enables students to understand spoken language and actively participate in an ESL conversation either at college or at home.

Teachers' questions. Teachers' questions are explicit pedagogical devices and instructional cues that elicit students' understanding and attention to the topic. In ESL classrooms, where language learning is the primary goal, questions are regarded as input because asking and answering questions are considered language in both communication and cognitive activities (Hestenes, Cassidy, \& Niemyer, 2004, Noor, Aman, \& Mustaffa, 2011). Being regarded as functioning input, questions should be comprehensible to learners to facilitate their meaningful interaction with ESL. Teachers' questions in the classroom can be directed to various targets: individuals, groups of students, or the entire class (Rezaee \& Farahian, 2012) in order to develop interactive ESL listening. Teachers' questions also provoke students' interest to actively participate in the learning process and serve as an invitation to confirm and clarify students' 
understanding.

Cooperative learning. Researchers such as Huss, (2006), Slavin, (2008) and Herrmann (2013) contend that interactive ESL listening could be developed when lecturers use cooperative learning through group work and pair work wherein gifted students work with low-achieving students. In this case, students are engaged in a constructive discussion to complete the task with their peers, which eventually lead students to develop new knowledge because they take turns uncovering and enhancing their understanding of the learning materials. In this type of activity, students identify their abilities and responsibilities through successfully completing the activity whenever they are actively engaged in a discussion (Hillyard, Gillespie, \& Littig, 2010). This type of classroom interaction increases students' motivational levels because students feel more comfortable working in a small group than working alone; such increases when students work together and exchange messages through questioning and answering routines in groups (Willis, 2007; Krause, Stark \& Mandl, 2008). This interaction could be achieved through the use of varied instructional techniques such as assessing students' listening skills through watching movies, presentations, role plays and listening to a radio program in an interactive listening ESL classroom. Finally, teacher-student interactions through cooperative learning enriches students' communicative competence and social responsibility as they develop their ESL listening.

Students' questions. Student questions are motivating tools which enable students to make sense out of what is being taught, confirm their understanding, and become active participants. King (1992) believed that having students ask and answer high-level questions facilitates their comprehension of the text material by engaging them in tasks that focus their attention on conceptualizing new knowledge with prior knowledge in order to maximize their understanding. Student questions serve as an awakening tool for lecturers to better understand students' involvement in the learning process because students will be able to express their understanding and teachers will become familiar with other parts of the lesson where they need to spend more time. Questions create a critical thinking environment in class that respects students' answers and interpretations in an attempt to construct and process information (Olsher \& Kantor , 2012).

This view is supported by Crosskey and Vance (2011) who believed that using students' understanding as a point of departure encourages them to raise questions that optimize their learning and engagement. This can be achieved by acknowledging the significance and richness of students' questions through praising students with phrases such as "what a good question" or "thank you for asking such a great question" whenever a student asks a question. Clearly, Barry (2007) supported the above technique by concluding that constantly talking and listening to students' thoughts could lead to successful ESL learning and increased motivation. Lecturers should encourage students to respond to one another, rather than merely to lecturers. When a student is speaking, lecturers should look around the room, not just at the student who is speaking. Making eye contact with other students lets them know that they are expected to be listening and formulating responses. The findings of this paper suggest that participatory approach serves as a crucial vehicle that exposes students to varied learning opportunities inside and outside of the classroom.

\section{Discussion of Results}

The purpose of this paper is to understand and find inclusive learning and teaching strategies that seek to develop interactive ESL listening for successful ESL learning. The main purpose of using interactive learning is to create a critical learning environment where learners have ample opportunities to share and express their ideas and take control of their own learning as a way of enhancing their ESL interactive listening skills. The discussion of the results of this paper is presented through the category of the development of interactive ESL listening with the following sub-categories: teacher talk, teachers' questions, cooperative learning and students' questions which emerge from the analysis of this paper and answering my research questions.

Teacher talk and teachers' questions. The results of this study demonstrate that teacher talk and teachers' questions elicit students' use of English through speech production, which develops their ESL listening capabilities. Questions provide teachers with feedback regarding how well and how much students learned as well as what needs to be retaught. Questions in ESL classrooms serve lecturers and students as devices for checking students' background knowledge. As Walsh and Sattes (2005) concluded, assessing students' knowledge is a major role of teacher questions. Teacher talk also helps teachers assess the learner's language ability, review the learned content and skills, and emphasizes important points. Furthermore, teacher's questions and teacher talk in ESL classrooms could be viewed as methods that teachers employ to create and continue teacher-student relationships. For example, in Cabrera and Matinez's (2001) study, teachers repeat and paraphrase utterances as well as simplify speech to develop student ESL listening skills. All these techniques put an emphasis on both input simplification and interactional modification. This paper also finds that repetitive listening materials can be more helpful for interactive ESL listening development if teachers set achievable goals for each listening task, using effective time management while allowing students to discuss 
the text.

Cooperative learning. This paper shows that cooperative learning through group work and pair work encourage a non-threatening, collaborative environment for learning, in which students work together to ask each other questions, debate topics, share ideas and learn from each other. Equally important, this kind of interaction between ESL students encourages them to be more responsible and accountable for their achievement while cooperatively assessing their own progress and each other. It also encourages students to choose appropriate learning strategies that best suit their learning abilities to develop their ESL listening (Vasiljevic, 2010). This view is supported by Pang (2010) who asserted that in order to develop a sustainable constructivist-active learning environment that motivates, engages, and equips learners; lecturers should emphasize cooperative learning, shared thinking and reasoning to build on existing knowledge. This approach is effective in developing ESL listening. Finally, this paper demonstrates the need for listening materials that explicitly enable students to integrate their own listening strategies in any form of interaction or contact with ESL either in class or outside for successful practice and acquisition.

Students' questions. The study by Demirel found that students' questions are motivating factors that enable lecturers to consider individual student learning ability (as cited in Gocer, 2010). This means that teachers should use students' questions as devices to assess students' understanding, to maintain the instructional environment and to promote interaction. Clearly, the findings of this paper convey that the use of student questions is essential for student motivation because they tend to encourage students to uncover their ideas, reflect their understanding, and promote communication from diverse angles. Using questions in this way can act as a stimulus that leads ESL students to use the target language via verbal exchange. Students' questions lead to the negotiation of meaning to produce comprehensible output, which afford ESL students with many opportunities to enhance their understanding of the content and proficiency. Certainly, students' questions and comprehensible output have considerable influence on student motivation and ESL listening only if students are given more communicative tasks to negotiate meaning with peers and teachers. This type of communicative interaction promotes ESL students' practice and language usage which lead to students' improved performance and motivation to actively engage in learning.

\section{Conclusion}

The main purpose of using interactive learning approach for developing interactive ESL listening skills is to create a classroom environment where learners have optimal opportunities to communicate and construct ESL learning. The results of this study show that methods springing from both progressive education and critical pedagogy support the theory that a democratic classroom will lead to more engaged students. From the findings, this paper agrees with Counts' work (as cited in Simmons \& Page, 2010) in that- there is a strong indication that asking of questions either by teachers or students is found to consistently maintain a significant role in the teaching-learning process. Such questions initiate small talk and lead to a wide range of positive outcomes including: heightened levels of student preparedness for lessons, assessment of prior knowledge and students' perceived learning, motivating students to share ideas in both formal and casual conversation, assessing teacher immediacy, and providing instrumental feedback to students in interpersonal skills. This means that questions have a positive impact on students' academic practices and are crucial elements for creating a positive classroom environment.

In light of developing ESL listening, this study finds that cooperative learning and lecturer talk help students to engage freely in a class discussion and uncover their potential to succeed. This makes the interactive learning approach a crucial paradigm which helps individual students to understand the rationale behind another student's utterance and feelings towards a given topic. Similarly, this paper finds that Paulo Freire's participatory approach in an ESL classroom shares the ideals of having a strong focus on students as multidimensional. It also helps students to be familiar with their personal learning processes by continuously monitoring their own performance while negotiating meaning with peers and teachers (Frey \& Fisher, 2010). Due to the concurrence of input and interaction, empirical studies in ESL learning should be based on language learning discourse and social interaction.

Most of all, the findings of this study support the teaching philosophy embedded in a post-method approaches, which critically favors students' background as something that needs to be considered by ESL teachers. Therefore, the concept of "teaching" cannot be treated in isolation, but should be integrated with "learning" to attain the desired outcomes. We strongly believe in a shared knowledge paradigm during ESL teaching since learners have so much to contribute to their learning when considered important contributors or stakeholders in their education rather than a mere audience. 


\section{Recommendations}

The results of this paper reveal that meaningful interactions between lecturers and students in the classroom are important aspects of effective communication and they are also elements of increased motivation and the development of greater interactive ESL listening skills. Therefore, this study recommends that lecturers should explicitly construct conditions for authentic usage of ESL in order to form the connections between what is taught in class and what they wish to do with ESL knowledge outside of the classroom. Due to these reasons, lecturers should utilize students' goals as a point of departure in designing communicative activities to increase student motivation.

A second recommendation is to develop interactive ESL listening in students by encouraging students to use ESL spontaneously to describe feelings and share ideas and opinions in order to improve their levels of practical proficiency. Thus, lecturers should build on strategies students already use and provide choices by negotiating with them in deciding, which communicative materials and activities work best for them in a positive atmosphere and community building activities.

Finally, since we live in a technologically advanced society, I recommend that teachers should utilize technology where possible to improve their students' motivation and ESL listening. This could be achieved by using social constructivist approach where the learning and teaching objectives are manifest in interactive activities that are coconstructed by teachers and students. However, it is worth-noting that this method alone is not sufficient when attempting to motivate students because a lecturer's rapport with his or her students also plays a significant role on their motivation.

\section{References}

Barry, N. H. (2007). Motivating the reluctant student. The American Music Teacher, 56(5): 23-27.

Blackburn, J. (2000). Understanding Paulo Freire: Reflections on the origins, concepts, and possible pitfalls of his educational approach. Community Development

Journal, 35(1), 3-15.

Cabrera, M., \& Martinez, P. (2001). The effects of repetition, comprehension checks, and gestures on primary school children in an EFL situation. ELT Journal, 55: 281-288.

Crosskey, L., \& Vance, M. (2011). Training teachers to support pupils' listening in class: An evaluation using pupil questionnaires. Child Language Teaching and Therapy, 27, 165-182.

Cullen, R. (2002). Supportive teacher talk: The importance of the F-move. ELT Journal, 56(2), 117-127

Franzosi, R. (2003). From words to numbers. Cambridge, England: Cambridge University Press.

Gocer, A. (2010). A qualitative research on the teaching strategies and class applications of the high school teachers who teach English in Turkey as a foreign language.

Education, 131(1), 196-219.

Frey, N., \& Fisher, D. (2010). Motivation requires a meaningful task. English Journal, 100(1): 30-36.

Herrmann, K.J. (2013). The impact of cooperative learning on student engagement: Results from an intervention. Active Learning in Higher Education, 14(3) 175-187

Hestenes, L., Cassidy, D., \& Niemyer, J. (2004). A macroanalysis of teachers' verbalizations in inclusive classrooms. Early Education and Development, 15(1), 23-38.

Hillyard, C., Gillespie, D. \& Littig, P. (2010). University students' attitudes about learning in small groups after frequent participation. Active Learning in Higher Education, 11, 9-20.

Huss, J. A. (2006). Gifted Education and Cooperative Learning: A Miss or a Match? Gifted Child Today, 29(4), 19-23.

Incecay, G. (2010). The role of teacher talk in young learners' language process. Procedia Social and Behavioral Sciences, 2(2), $277-$ 281.

King, A. (1992). Comparison of self-questioning, summarizing, and notetaking- review as strategies for learning from lectures. American Educational Research Journal, 29(2), 303-323.

Krause, U., Stark, R., \&, Mandl, H. (2008). The effects of cooperative learning and feedback on e-learning in statistics. Learning and Instruction, 19(2009), 158-170.

Lee, Y. (2006). Third turn position in teacher talk: Contingency and the work of teaching. Journal of Pragmatics, 39(1), 180-206.

Lewis-Beck, M. S., Bryman, A., \& Liao, T. F. (2004). The SAGE Encyclopedia of Social Science Research Method (vol. 1-3). Thousand Oaks, CA: Sage.

McCombs, B. L., \& Miller, L. (2007). Learner-centered classroom practices and assessments:Maximizing student motivation, learning, and achievement. Thousand Oaks, CA: Corwin Press.

Noor, N. M., Aman, I., \& Mustaffa, R. (2011). Teachers' Questioning Approaches in the Malaysian ESL Classroom. The International Journal of Learning, 18(7), 313-326.

Olsher, G., \& Kantor, I. (2012). Asking Questions as a Key Strategy in Guiding a Novice Teacher: A self-study. Studying Teacher Education: A journal of self-study of teacher education practices, 8(2), 157-168

Pang, K. (2010). Creating stimulating learning and thinking using new models of activity-based learning and metacognitive-based 
activities. Journal of College Teaching \& Learning, 7(4), 29-38.

Patton, M. Q. (2002). Qualitative research and evaluation methods. Thousand Oaks, CA: Sage.

Rezaee, M., \&, Farahian, M. (2012). An Exploration of Discourse in an EFL Classroom:

Teacher Talk. Procedia Social and Behavioral Sciences, 47, 1237-1241.

Schlebusch, G., \& Thobedi, M. (2004). Outcomes-Based Education in the English Second Language Classroom in South Africa. The Qualitative Report Volume 9(1), 35-48.

Sharpe, T. (2008). How can teacher talk support learning? Linguistic and Education, 19(2), 132-148.

Simmons, A. M., \& Page, M. (2010). Motivating students through power and choice. English Journal, 100(1), 65-69.

Swain, K. D. Friehe, M., \& Harrington, J. M. (2004). Teaching listening strategies in the inclusive classroom. Intervention in School \& Clinic, 40(1), 48-54.

Timulak, T. (2009). Meta-analysis of qualitative studies: A tool for reviewing qualitative research findings in psychotherapy. Psychotherapy Research, 19(4-5), 591-600.

Thompson, K., Leintz, P., Nevers, B., \& Witkowski, S. (2004). The interactive listening model: An approach of teaching and learning listening. The Journal of General Education, 53(4), 226-240.

Walsh, J., \& Sattes, B (2005). Quality questioning: Research-based practice to engage every learner. Thousand Oaks, CA: Corwin Press.

Willis, J. (2007). Cooperative learning is a brain turn-on. Middle School Journal, Education, 38(4) 4-13.

Vasiljevic, Z. (2010). Dictoloss as an intensive method of teaching listening comprehension to L2 Learners. English Language Teaching, 3(1), 41-52. 
